\title{
Article \\ Numerical and Experimental Study on Suppression Effect of Acoustic Black Hole on Vibration Transmission of Refrigerator Compressor
}

\author{
Xiaofei Du ${ }^{1}{ }^{\circledR}$, Qidi Fu ${ }^{2}$, Jianrun Zhang ${ }^{2}$ and Chaoyong Zong ${ }^{3, *}$ \\ 1 School of Mechanical Engineering, Nanjing Institute of Technology, Nanjing 211167, China; \\ duxiaofei@njit.edu.cn \\ 2 School of Mechanical Engineering, Southeast University, Nanjing 211189, China; qidi_fu@163.com (Q.F.); \\ zhangjr@seu.edu.cn (J.Z.) \\ 3 School of Mechanical Engineering, Dalian University of Technology, Dalian 116024, China \\ * Correspondence: zong_chaoyong@mail.dlut.edu.cn
}

Citation: Du, X.; Fu, Q.; Zhang, J.;

Zong, C. Numerical and

Experimental Study on Suppression

Effect of Acoustic Black Hole on

Vibration Transmission of

Refrigerator Compressor. Appl. Sci.

2021, 11, 8622. https://doi.org/

10.3390/app11188622

Academic Editor: Tai-Yan Kam

Received: 11 August 2021

Accepted: 15 September 2021

Published: 16 September 2021

Publisher's Note: MDPI stays neutral with regard to jurisdictional claims in published maps and institutional affiliations.

Copyright: (c) 2021 by the authors. Licensee MDPI, Basel, Switzerland. This article is an open access article distributed under the terms and conditions of the Creative Commons Attribution (CC BY) license (https:/ / creativecommons.org/licenses/by/ $4.0 /)$.

\begin{abstract}
The acoustic black hole (ABH) structures have the potential to achieve structural vibration suppression and noise reduction through the effect of the $\mathrm{ABH}$ on the concentration and manipulation of flexural waves. In this paper, a new solution is proposed to embed 2-D ABHs on the support plate to suppress the transmission of compressor vibration to the refrigerator body. The vibration and acoustic measurement experiment of the compressor, the support plate and the refrigerator body, and the coherence analysis of the vibration signals and acoustic signal are carried out to determine the influence of the compressor vibration on the vibration of the refrigerator body and the radiation sound of the back wall. The concentration and manipulation effects of 2-D ABH on flexural waves are verified by numerical simulation of flexural wave propagation in the time domain. FEM models of the original support plate and the damping $\mathrm{ABH}$ support plate are established to investigate the comprehensive effect of the 2-D ABHs and the damping layers on the vibration characteristics of the support plate through vibration modal and dynamic response analysis. Numerical simulation results show that the 2-D damping ABHs can suppress the vibrations generated by the compressor at specific frequencies in the middle and high-frequency bands from being transmitted to the refrigerator body through the support plate.
\end{abstract}

Keywords: acoustic black hole; vibration suppression; flexural wave; support plate; refrigerator compressor

\section{Introduction}

In the past two decades, as a new type of passive vibration reduction and noise attenuation technology, the acoustic black hole $(\mathrm{ABH})$ was studied a lot in terms of theoretical development, modeling and simulation, and analysis of vibration and acoustic characteristics, and it is expected to provide a new solution to the problems of vibration and noise in engineering [1-5]. Mironov found in a thin wedge-shaped structure that if the thickness of the structure is reduced in a certain power exponential form (the power exponent is not less than 2), the velocity of the flexural wave in the structure will gradually decrease as the thickness of the structure decreases [6]. Ideally, the velocity of the flexural wave can be reduced to zero to achieve zero reflection. Krylov first proposed the concept of an "acoustic black hole" to describe the above phenomenon and applied the ABH to beam and plate structures. Krylov used the geometric acoustic method [7,8] and experimental method [9] to study the characteristics of ABH structure, such as flexural wave propagation, vibration suppression, and sound radiation reduction. The $\mathrm{ABH}$ structure can achieve the concentration and manipulation effects of flexural waves in solid structures in a wide frequency range, thereby achieving vibration reduction and noise attenuation; in addition, it also contributes to the light-weighting of the structures [10]. 
There is much research on the vibration characteristics of the ABH structures. Tang et al. established a semi-analytical model by using Mexican wavelet function to fit the sharply changing wave group at the edge of the $\mathrm{ABH}$ to analyze the vibration characteristics of one-dimensional $\mathrm{ABH}$ structure and studied the influences of damping layer thickness and damping layer stiffness on the dynamic response of the ABH structure [11,12]. Deng et al. established a dynamic model of the truncated one-dimensional $\mathrm{ABH}$ beam containing passive constrained viscoelastic layers (PCVL) using the semi-analytical method, and both the analysis and the experimental results show that the truncated one-dimensional ABH beam with PCVLs can achieve better vibration attenuation effects than the one covered with a viscoelastic damping layer [13]. Deng et al. also analyzed the influence of ABH parameters on the vibration characteristics of the two-dimensional $\mathrm{ABH}$ circular plate based on the semi-analytical method [14]. Additionally, they studied the vibration response of the new ring-shaped two-dimensional $\mathrm{ABH}$, and the results showed that the ring-shaped $\mathrm{ABH}$ exhibited excellent vibration isolation performance over the entire frequency range [15]. Ma et al. established a semi-analytical model to analyze the vibration of a two-dimensional $\mathrm{ABH}$ plate and used the Daubechies wavelet function to express the lateral displacement of the plate in enhancing the effectiveness of the Rayleigh-Ritz method [16]. Based on the approximate analytical method, $\mathrm{O}^{\prime}$ boy et al. analyzed the frequency response characteristics of a square plate containing a two-dimensional square $\mathrm{ABH}$ [17] and a circular plate containing a two-dimensional circular $\mathrm{ABH}$ [18] and investigated the influence of the damping layer. The result shows that the cross mobility reaches $17 \mathrm{~dB}$ attenuation at the resonance peaks. Conlon arranged multiple two-dimensional ABHs in a thin plate with a certain periodicity and analyzed the vibration response of the plate by establishing a finite element model [19]. Zhao et al. evaluated the vibration performance of the thin-walled $\mathrm{ABH}$ structure under transient and steady-state excitation through numerical simulation and experimental methods [20], and both the numerical and experimental results show that the proposed structure can achieve an efficient and broadband vibration attenuation performance. Gao et al. proposed a V-shaped folded $\mathrm{ABH}$ beam, and the numerical simulation and experimental results show that the $\mathrm{V}$-shaped folded $\mathrm{ABH}$ beam has an ultra-wide and complete band gap below $1 \mathrm{kHz}$, which is expected to be used for low-frequency vibration reduction and wave attenuation [21]. Feurtado et al. experimentally measured the average mobility and radiated sound power of the surface of the aluminum plate embedded with 20 two-dimensional ABH arrays attached with damping layers [22]. The results showed that compared with the reference plate of uniform thickness, the average surface mobility of the fully damped $\mathrm{ABH}$ plate is reduced by up to $14 \mathrm{~dB}$. Bowyer et al. experimentally studied the influence of the power-law contour grooves in the plate on the damped flexural vibration of the one-dimensional $\mathrm{ABH}$ structure [23] and carried out experiments to study the vibration response of the two-dimensional $\mathrm{ABH}$ structures, mainly including rectangular and circular $\mathrm{ABH}$ plates which are made of steel, aluminum or composite materials and contain circular indentations or dimples wedge [24,25]. Besides, traditional ABH structures cannot be changed to different frequencies, and Ning et al. found that the active control can be applied to black hole characteristics of the flexural wave, which can provide a much wider frequency region $[26,27]$.

The acoustic black hole can concentrate flexural waves in the structure at or near the $\mathrm{ABH}$ region, and with the help of the damping layer or other additional components to dissipate flexural wave energy, it can achieve a good effect of suppressing structural vibration with a very small amount of damping layer. However, most of the current research on $\mathrm{ABH}$ still stays in the basic theory, and expanding the application research of $\mathrm{ABH}$ structures in different engineering fields to achieve better vibration reduction effects in practice is one of the main issues needed to be studied for the ABH [28]. The compressor is the core component of the refrigerator, and when the compressor works, the internal motor drives the piston to reciprocate. At this time, the working torque of the piston, the unbalanced moment of inertia of the structure, the friction between the moving pairs, the electromagnetic force inside the motor, etc., can all cause vibration [29], and the 
generated vibration is transmitted to the compressor shell and further to the support plate and the body of the refrigerator. The vibration of the compressor is the main source of vibration for all types of refrigerators. Since the refrigerator compressor is generally a fully enclosed structure, it is often difficult to optimize internal structures to reduce compressor vibration. Therefore, blocking the transmission of compressor vibration to the refrigerator body as much as possible is an important method to solve such problems. The support plate is an important component connecting the compressor and the refrigerator body, and almost all vibrations generated by the compressor are transmitted to the refrigerator body through the support plate. Utilizing the concentration effect of the $\mathrm{ABH}$ on flexural waves, it is expected to concentrate the vibration energy of the compressor in the $\mathrm{ABH}$ region by embedding $\mathrm{ABHs}$ on the support plate. At this time, the gathered vibration energy cannot be transferred to the refrigerator body through the support plate. Therefore, it is feasible to apply the $\mathrm{ABH}$ to suppress the propagation of refrigerator compressor vibration.

In this paper, the vibration and noise measurement and analysis of key components such as the compressor and the support plate were carried out, and then the damping $\mathrm{ABHs}$ were embedded in the support plate, and the effect of the damping ABHs in suppressing the vibration transmission of the compressor was studied through numerical simulation. It is expected to provide a certain reference and guidance for the application of $\mathrm{ABH}$ in the field of home appliances for vibration reduction. To our best knowledge, this paper is the first to study the vibration suppression effect of $\mathrm{ABH}$ on refrigerators.

\section{Measurement of Acoustic and Vibration Characteristics of Key Components of Frost-Free Refrigerator}

Figure 1 shows the physical image of the back of the frost-free refrigerator. The dimensions of the refrigerator are: $1722 \mathrm{~mm}$ (height) $\times 910 \mathrm{~mm}$ (width) $\times 610 \mathrm{~mm}$ (length). The compressor, condenser, and condenser fan are all fixed on the support plate at the bottom, and the support plate and the refrigerator body are connected by bolts. The refrigerant absorbs the heat in the refrigerator at the evaporator, and then the temperature of the refrigerant rises and flows back to the compressor [30]. The compressor provides power to transport the refrigerant to the condenser for heat dissipation and cooling and then flows to the evaporator again for heat exchange and reciprocating circulation.

To investigate the vibration of the refrigerator compressor and its influence on the vibration and radiated sound of the refrigerator body, the vibration and acoustic measurement experiment of the compressor, the support plate, and the refrigerator body was carried out. The physical image of the experimental platform is shown in Figure 2. The measured vibration and acoustic signals can be used to analyze the transmission of the compressor vibration and the influence of the compressor vibration on the radiated sound of the refrigerator body, and they will also be used as the excitation input for subsequent numerical simulations. Six unidirectional acceleration sensors are placed on the surface of the compressor, the four positions on the support plate connected to the compressor, and the center position on the back of the refrigerator, and an acoustic sensor is placed $0.8 \mathrm{~m}$ behind the back of the refrigerator (the vertical distance between the acoustic sensor and the ground is also $0.8 \mathrm{~m}$ ). The sensor types and the location of the measuring points are listed in Table 1 . The $\mathrm{m}+\mathrm{p}$ measurement system is used to measure the vibration of the refrigerator compressor, support plate, and the sound and vibration of the back wall of the refrigerator. Both the acceleration sensors and the acoustic sensor are connected to the $m+p$ VibPilot. The $m+p$ VibPilot can collect the time-domain signals of each sensor and transmit them to the laptop computer, and then use the SO Analyser software to process and further analyze the time-domain signals. 


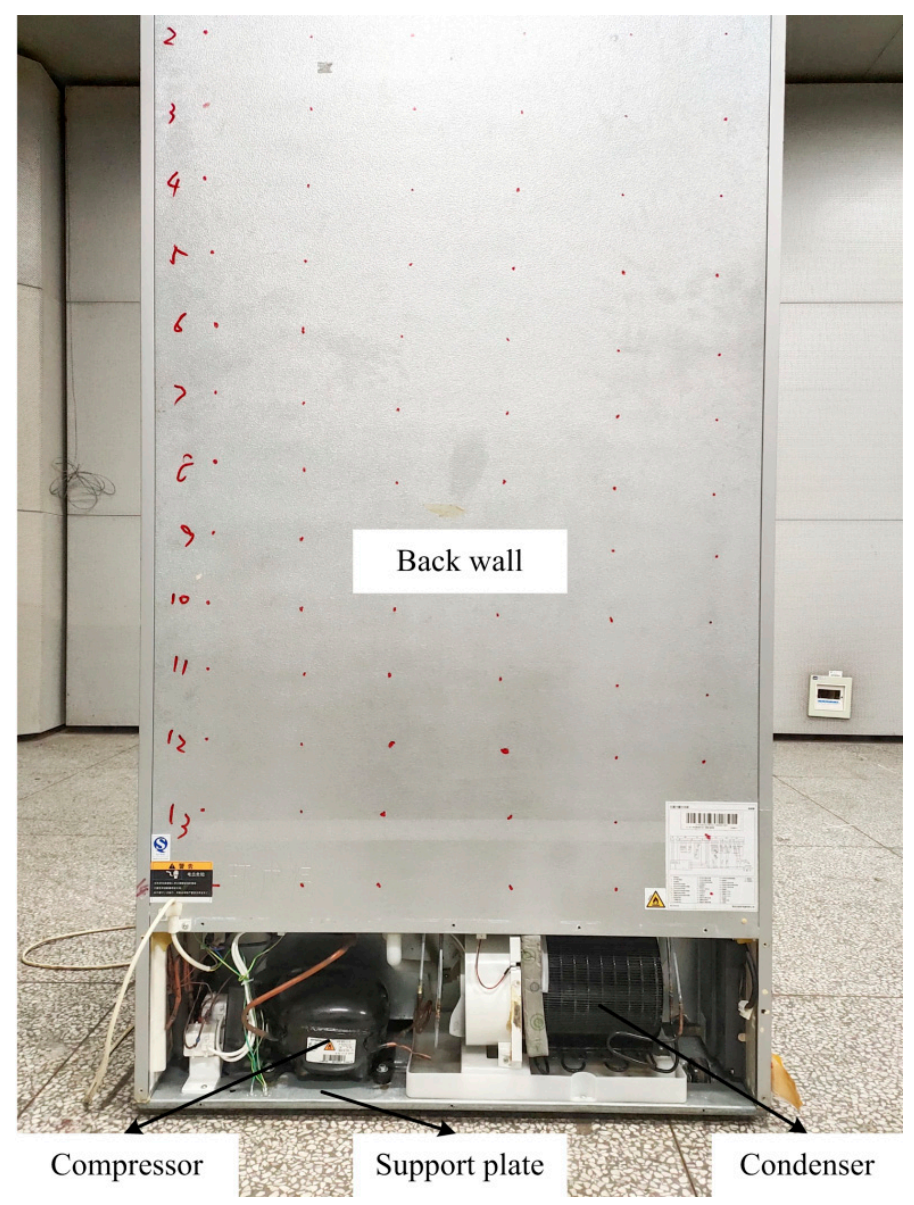

Figure 1. The physical image of the back of the refrigerator.

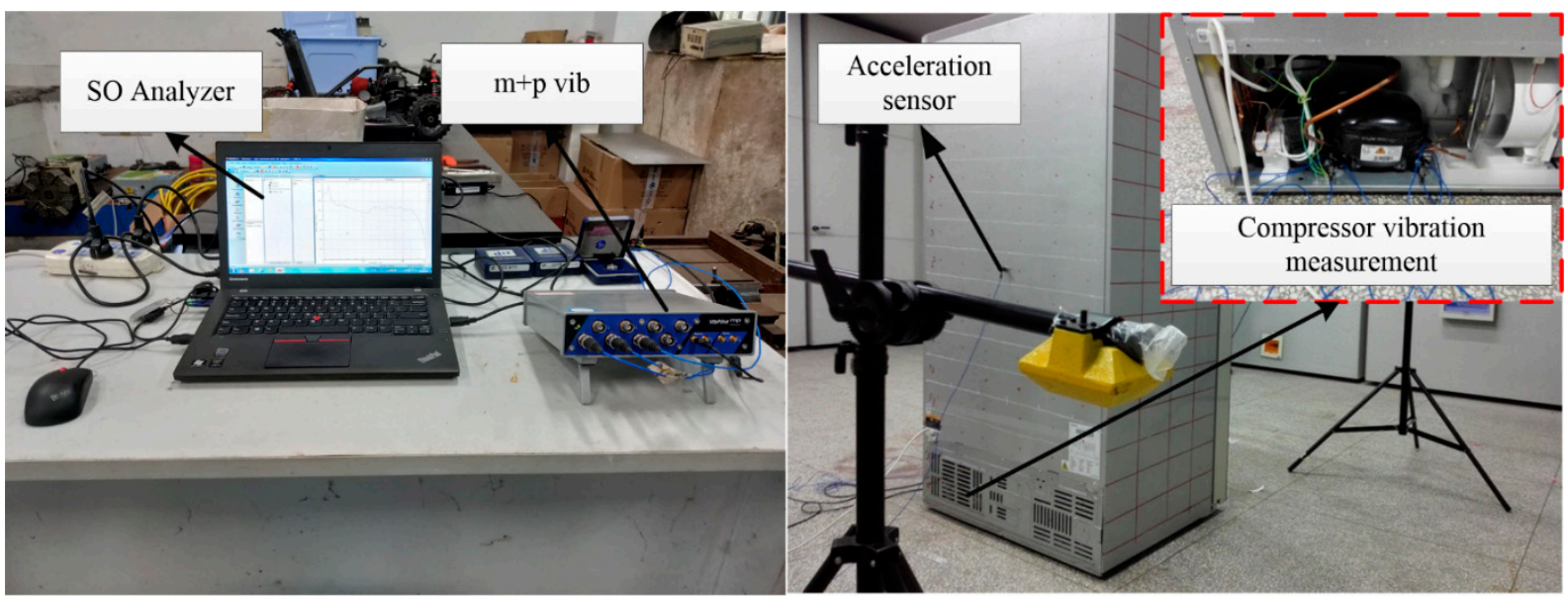

Figure 2. The physical image of the vibration and acoustic measurement experimental platform. 
Table 1. Sensor type and measuring point location.

\begin{tabular}{ccc}
\hline $\begin{array}{c}\text { Measuring Point } \\
\text { Number }\end{array}$ & Sensor Type & Measuring Point Location \\
\hline 1 & Unidirectional acceleration sensor & $\begin{array}{c}\text { First position on the support plate } \\
\text { connected to the compressor }\end{array}$ \\
\hline 2 & Unidirectional acceleration sensor & $\begin{array}{c}\text { Second position on the support } \\
\text { plate connected to the compressor }\end{array}$ \\
\hline 3 & Unidirectional acceleration sensor & $\begin{array}{c}\text { Third position on the support plate } \\
\text { connected to the compressor }\end{array}$ \\
\hline 5 & Unidirectional acceleration sensor & $\begin{array}{c}\text { Fourth position on the support } \\
\text { plate connected to the compressor }\end{array}$ \\
\hline 6 & Unidirectional acceleration sensor & Compressor surface \\
\hline 7 & Unidirectional acceleration sensor & $\begin{array}{c}\text { The outer wall of the back of } \\
\text { the refrigerator }\end{array}$ \\
\hline & Acoustic sensor & $\begin{array}{c}\text { 0.8 } \mathrm{m} \text { from the back of } \\
\text { the refrigerator }\end{array}$ \\
\hline
\end{tabular}

Figures $3-5$ show the vibration acceleration spectrum of the compressor surface, the vibration acceleration spectrum of the outer wall on the back of the refrigerator, and the 1/3-octave frequency spectrum of the radiated sound from the outer wall on the back of the refrigerator. The acoustic measurement experiment was carried out in a semi-anechoic chamber from Landtop Faist, with a background noise of $12 \mathrm{~dB}$ (A). From these spectrograms, the main vibration frequencies and corresponding amplitudes of the compressor can be obtained, and the transmission of compressor vibration to the refrigerator body can also be studied. The 1/3-octave frequency spectrum of the radiated sound from the outer wall of the refrigerator is also used to analyze the coherence between the vibration of the compressor and the sound. The vibration acceleration frequency spectra of the four positions on the support plate connected to the compressor can be used as an excitation input in numerical modeling to study the effect of suppressing the vibration of the support plate before and after the ABHs embedded in the support plate.

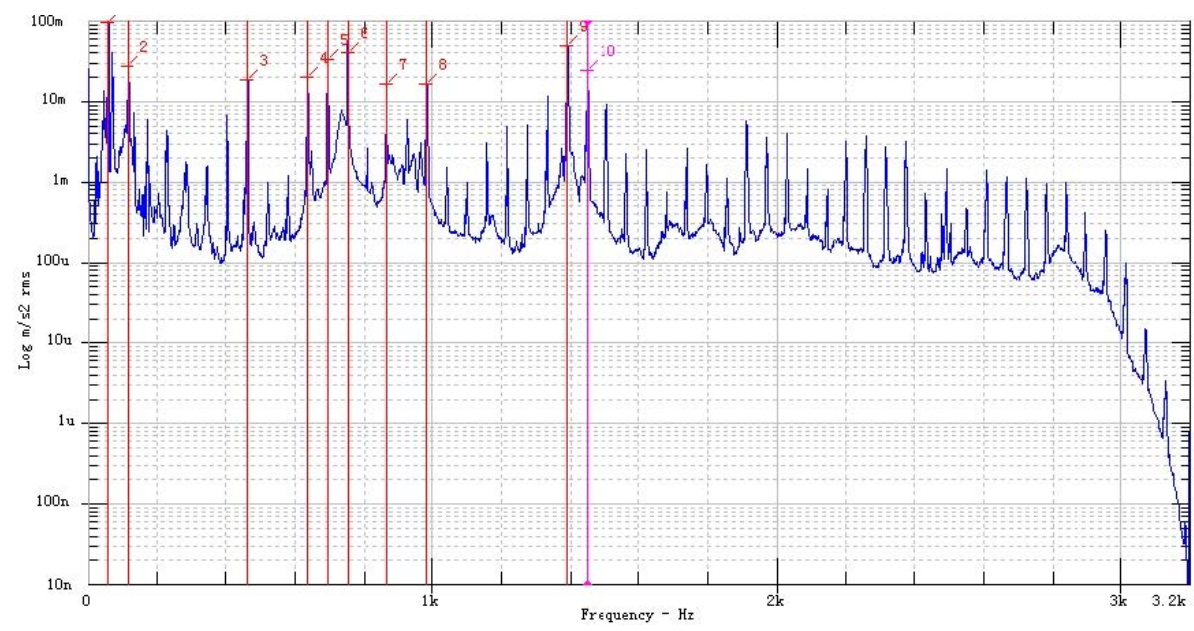

Figure 3. Acceleration spectrum of the vibration on the compressor surface. 


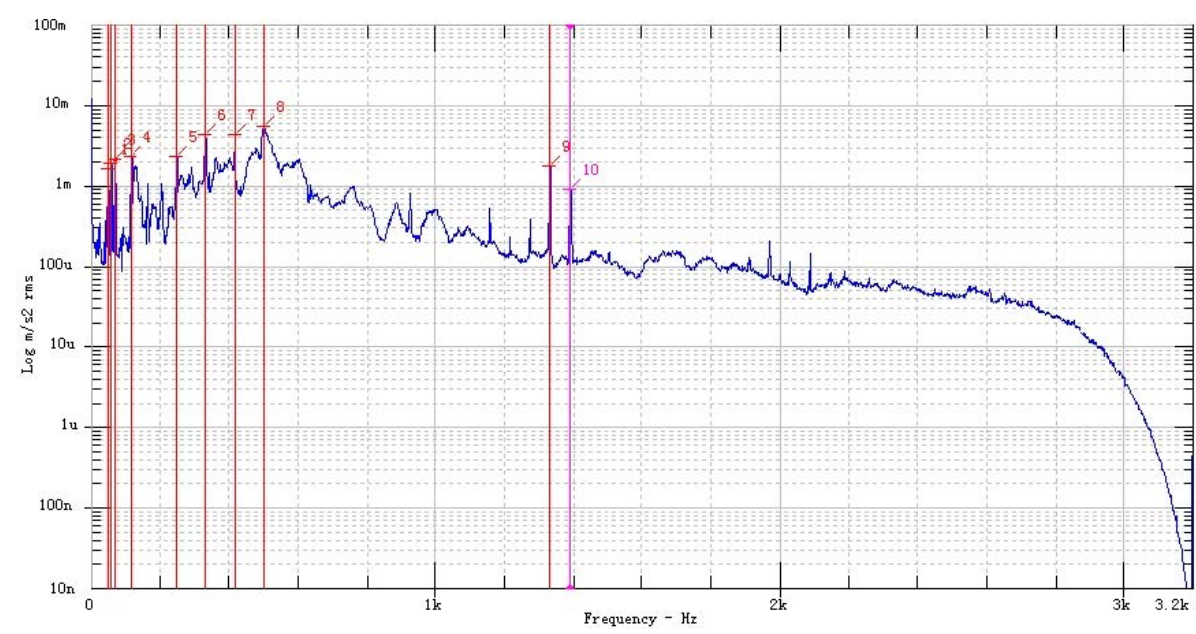

Figure 4. Acceleration spectrum of the outer wall on the back of the refrigerator.

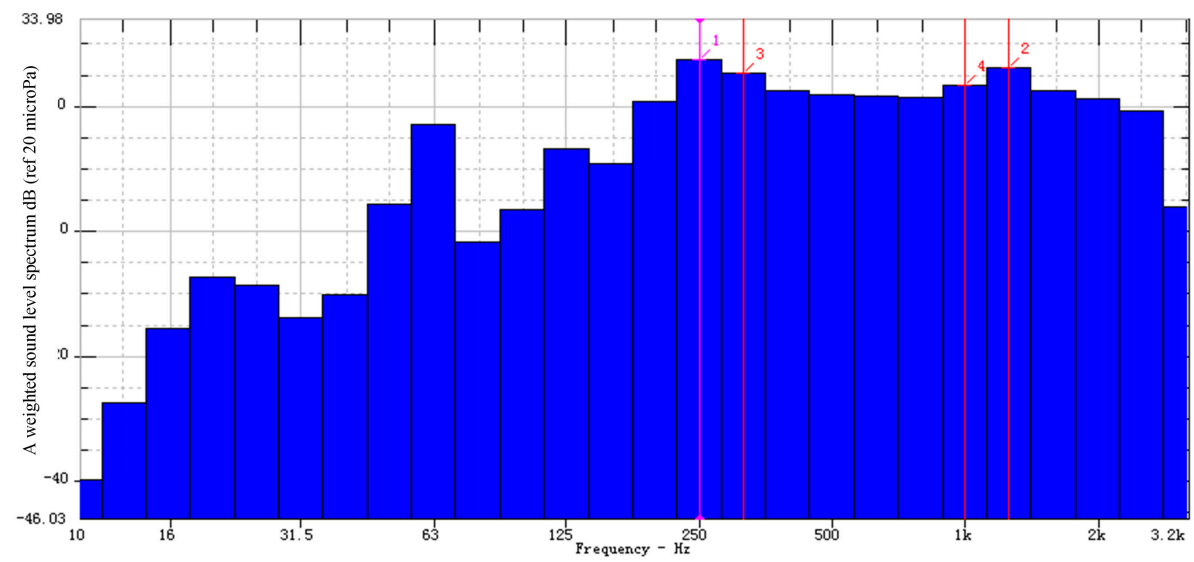

Figure 5. The 1/3-octave frequency spectrum of the radiated sound from the outer wall of the refrigerator.

\section{Coherence Analysis of Vibration and Noise}

The coherence theory can be used to analyze the radiated sound of the back wall of the refrigerator and the vibration acceleration signals of other measuring points to determine the main vibration source of the radiated noise. For the measurement in this paper, the radiated sound from the outer wall on the back of the refrigerator belongs to a multiple-input single-output system, which can be analyzed using a coherent power spectrum. The coherence function of the vibration acceleration signal $X(t)$ and the sound pressure signal $Y(t)$ is defined as [31]:

$$
\gamma_{X Y}(\omega)=\frac{\left|G_{X Y}(\omega)\right|}{\left|G_{X X}(\omega) \cdot G_{Y Y}(\omega)\right|^{1 / 2}}
$$

where $G_{X X}(\omega)$ and $G_{Y Y}(\omega)$ are the self-power spectra of the vibration acceleration signal and the sound pressure signal, respectively, $G_{X Y}(\omega)$ is the cross power spectrum of the vibration acceleration signal and the sound pressure signal.

The calculation equation of self-power spectral density $G_{X X}(\omega)$ is:

$$
G_{X X}(\omega)=\int_{-\infty}^{+\infty} R_{X X}(\tau) e^{-j \omega t} d \tau
$$

where $R_{X X}(\tau)$ is the self-correlation function $R_{X X}(\tau)=\lim _{\tau \rightarrow \infty} \frac{1}{\tau} \cdot \int_{0}^{\tau} x(t) \cdot x(t+\tau) d t$. 
The calculation equation of cross power spectral density $G_{X Y}(\omega)$ is:

$$
G_{X Y}(\omega)=\int_{-\infty}^{+\infty} R_{X Y}(\tau) e^{-j \omega t} d \tau
$$

where $R_{X Y}(\tau)$ is the cross-correlation function $R_{X Y}(\tau)=\lim _{\tau \rightarrow \infty} \frac{1}{\tau} \cdot \int_{0}^{\tau} x(t) \cdot y(t+\tau) d t$.

Since there is always some noise interference in the actual signals, the value of the coherence function between the measured signals is always less than 1 , and the closer the value of the coherence function is to 1 , the greater the degree of coherence between the sound radiated from the outer wall of the refrigerator and the vibration acceleration signal at that point; on the contrary, the closer the value of the coherence function is to 0 , the smaller the degree of coherence between the sound radiated from the outer wall of the refrigerator and the vibration acceleration signal.

Figure 6 shows the coherence function curve between the radiated sound of the back wall of the refrigerator and the vibration acceleration of the compressor surface. It can be seen from Figure 6 that the frequencies of the greater coherence between the radiated sound and the vibration signal are mainly concentrated at $57.813 \mathrm{~Hz}, 68.750 \mathrm{~Hz}, 117.19 \mathrm{~Hz}$, $637.50 \mathrm{~Hz}, 695.31 \mathrm{~Hz}, 1390.6 \mathrm{~Hz}, 2087.5 \mathrm{~Hz}$, and $2260.9 \mathrm{~Hz}$. At these frequencies, the coherence function values between the radiated sound of the back wall of the refrigerator and the vibration acceleration of the compressor surface are greater than 0.8 , which can be considered to have high coherence, that is, the structurally radiated sound at these frequencies is mainly caused by the vibration at the measuring point 5 .

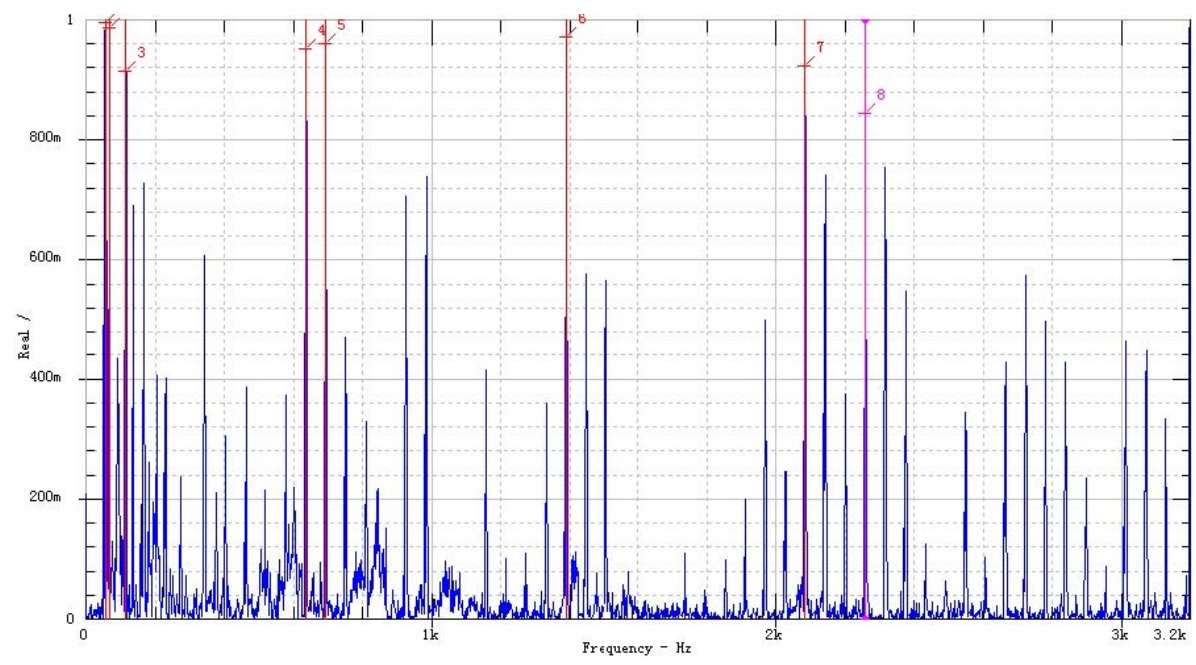

Figure 6. Coherence function curve between the radiated sound of the back wall of the refrigerator and the vibration acceleration of the compressor surface.

Figure 7 shows the coherence function curve between the radiated sound of the back wall of the refrigerator and the vibration acceleration on the back wall of the refrigerator. It can be seen from Figure 7 that the frequencies of the greater coherence between the radiated sound and the vibration signal are mainly concentrated at $57.813 \mathrm{~Hz}, 68.750 \mathrm{~Hz}$, $100 \mathrm{~Hz}, 115.63 \mathrm{~Hz}, 251.56 \mathrm{~Hz}, 1390.6 \mathrm{~Hz}$, and $2087.5 \mathrm{~Hz}$. At these frequencies, the coherence function values between the radiated sound of the back wall of the refrigerator and the vibration signal of the back wall of the refrigerator are also greater than 0.8 , which can be considered to have high coherence, that is, the structurally radiated sound at these frequencies is mainly caused by the vibration at the measuring point 6 . 


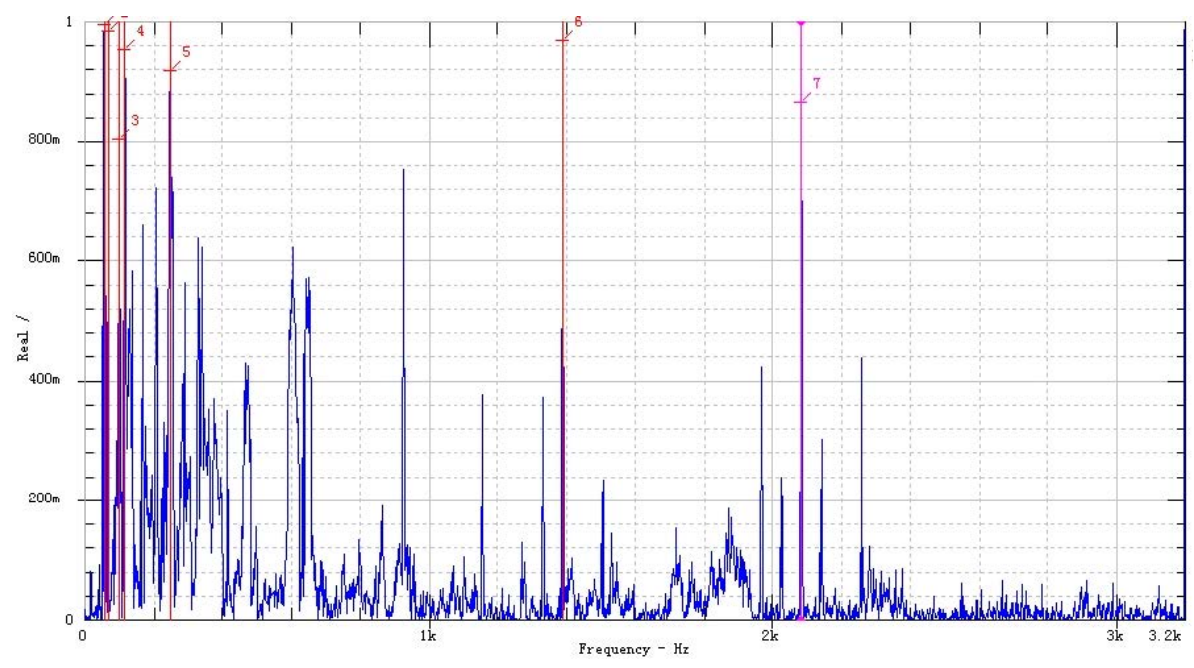

Figure 7. Coherence function curve between the radiated sound of the back wall of the refrigerator and the vibration acceleration on the back wall of the refrigerator.

By combining the 1/3-octave frequency spectrum of the radiated sound from the back wall of the refrigerator in Figure 5, it can be concluded that the radiated sound from the back wall of the refrigerator at $63 \mathrm{~Hz}, 125 \mathrm{~Hz}, 630 \mathrm{~Hz}, 1250 \mathrm{~Hz}, 2000 \mathrm{~Hz}$, and $2500 \mathrm{~Hz}$ is mainly caused by the vibration of the compressor, and the sound radiated from the back wall of the refrigerator at other center frequencies is less coherent with the vibration of the compressor. Therefore, after the above analysis, it can be concluded that the vibration of the compressor is transmitted to the refrigerator body through the support plate and causes the back wall of the refrigerator to radiate sound. Suppressing the transmission of the support plate to the vibration of the refrigerator compressor can significantly reduce the vibration of the refrigerator body and the radiation sound of the back wall of the refrigerator.

\section{Acoustic Black Hole Theory and Verification of the ABH Effect}

A two-dimensional (2-D) ABH was embedded on the rectangular elastic plate; the schematic diagram of the structure is shown in Figure 8. The thickness of the ABH plate can be expressed by the following equation:

$$
h(x)=\left\{\begin{array}{l}
\varepsilon x^{m}-b, \text { ABH region } \\
h_{p}, \text { Uniform region }
\end{array}\right.
$$
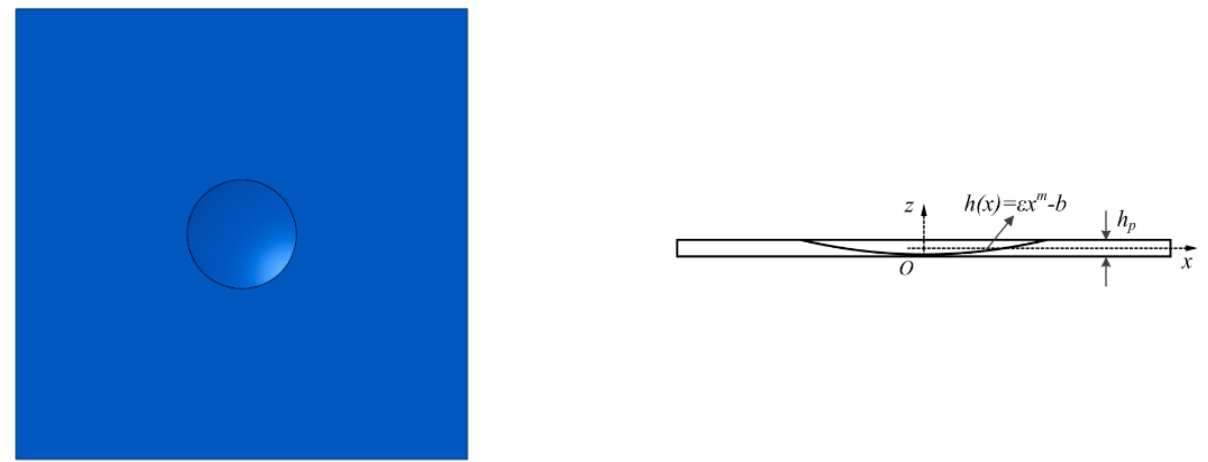

Figure 8. Schematic diagram of the 2-D ABH structure.

where $\varepsilon$ is a constant, and $m$ is the power exponent of the thickness change in the $\mathrm{ABH}$ region, $m \geq 2, b$ is the distance between the center of the $\mathrm{ABH}$ region and the coordinate origin in the $z$-axis direction, and the thickness of the uniform region of the $\mathrm{ABH}$ plate is $h_{p}$. However, due to the limitation of the processing technology, the ideal ABH structure cannot 
be produced in the actual manufacturing process, so there must be a truncation existing in the actual ABH structure. For the model in Figure 8, the thickness of the truncated region can be expressed as:

$$
h_{t}=\frac{h_{p}}{2}-b
$$

The existence of the truncation will significantly increase the reflection coefficient of the flexural wave. For an isotropic thin plate, the propagation speed of the flexural wave in the plate is:

$$
c_{B}=\left(B \omega^{2} / m\right)^{1 / 4}
$$

where $B$ is the bending stiffness of the $\mathrm{ABH}$ plate material, $B=E h(x)^{3} /\left[12\left(1-v^{2}\right)\right], E$ is the Young's modulus of the ABH plate material, $v$ is the Poisson's ratio; $\omega$ is the angular frequency, $m$ is the areal density of the $\mathrm{ABH}$ plate, $m=\rho_{m} h(x)$, and $\rho_{m}$ is the density of the $\mathrm{ABH}$ plate material. When the flexural wave propagates from the uniform region of the $\mathrm{ABH}$ plate to the $\mathrm{ABH}$ region, as the thickness of the plate gradually decreases, the velocity of the flexural wave also gradually decreases [32]. At this time, the wavelength is compressed, and the amplitude of the flexural wave gradually increases so as to achieve the concentration effect of the flexural wave.

In order to verify the concentration effect of the $\mathrm{ABH}$ plate on flexural waves, a square plate embedded with a 2-D ABH was designed. The geometric size of the ABH plate is $200 \times 200 \mathrm{~mm}$, the thickness of the uniform region is $4 \mathrm{~mm}$, and the coordinate origin is established at the geometric center of the middle plane in the thickness direction of the $\mathrm{ABH}$ plate. The thickness equation of the $\mathrm{ABH}$ region is $h(x)=0.006 x^{2}-1.5$. According to Equation (5), the thickness of the truncation of the $\mathrm{ABH}$ region is $0.5 \mathrm{~mm}$, and the outer diameter of the $\mathrm{ABH}$ region is about $48.3 \mathrm{~mm}$. The multi-physics simulation software COMSOL is used to carry out FEM modeling and numerical calculation of flexural wave propagation in the $\mathrm{ABH}$ plate. To ensure the calculation accuracy, the extremely fine level is used to mesh the 2-D ABH plate, and the $\mathrm{ABH}$ regions are encrypted to ensure that the number of grids in each wavelength is more than six.

The FEM model of the ABH plate is shown in Figure 9. The material of the 2-D ABH plate is 1060 aluminum, the Young's modulus is $69 \mathrm{GPa}$, the Poisson's ratio is 0.33 , and the density is $2710 \mathrm{~kg} / \mathrm{m}^{3}$. The left side face of the ABH plate is clamped, the remaining faces and edges are set as free boundaries, and the excitation point is located at the midpoint of the right side of the upper surface of the $\mathrm{ABH}$ plate. A simple harmonic excitation force perpendicular to the $\mathrm{ABH}$ plate is applied to the excitation point, the amplitude of the excitation force is $100 \mathrm{~N}$, the frequency is $80 \mathrm{MHz}$, and the action time is $0 \sim 2 \times 10^{-5} \mathrm{~s}$. The transient calculation of the flexural wave propagation in the $\mathrm{ABH}$ plate was carried out. The time length of the transient calculation is $0 \sim 5 \times 10^{-4} \mathrm{~s}$, and the time step is set to $1.5 \times 10^{-7} \mathrm{~s}$.

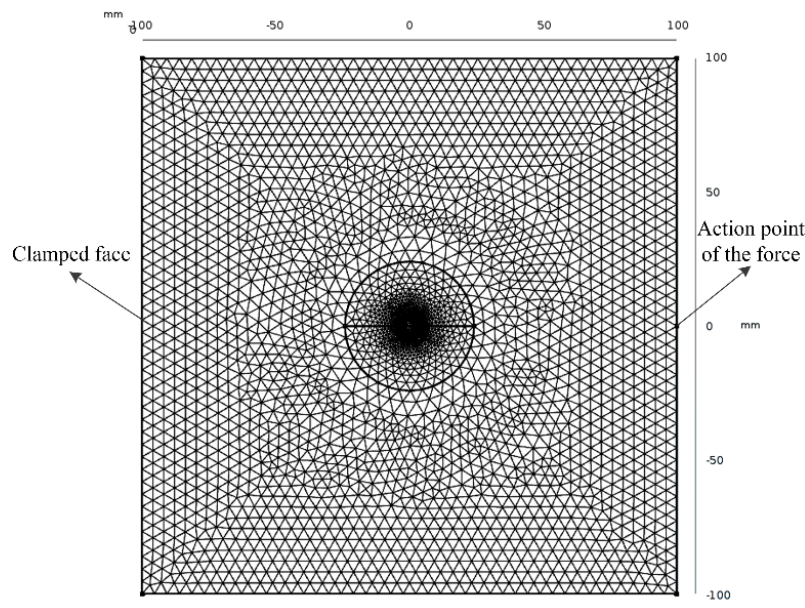

Figure 9. FEM model of the 2-D ABH plate. 
Figure 10 shows the stress distribution of the $\mathrm{ABH}$ plate at different times to characterize the propagation process of flexural waves in the $\mathrm{ABH}$ plate. It can be seen from Figure 10 that at $t=7.5 \times 10^{-5} \mathrm{~s}$, the flexural waves, excited by the force, begin to propagate in the plate, and there are obvious wave crests and troughs. At $t=1.2 \times 10^{-4} \mathrm{~s}$, the flexural waves propagate to the $\mathrm{ABH}$ region, the wavelength of the flexural wave is compressed, and an obvious concentration effect is produced. When $t=1.95 \times 10^{-4} \mathrm{~s}$, the flexural waves reached the upper and lower boundaries of the $\mathrm{ABH}$ plate and were reflected. At that time, the $\mathrm{ABH}$ region still had a significant aggregation effect on the flexural waves so that the flexural waves near the $\mathrm{ABH}$ region did not significantly continue to propagate to the left. When $t=2.31 \times 10^{-4} \mathrm{~s}$, the flexural waves transmitted to the two corners on the left side of the $\mathrm{ABH}$ plate, but due to the concentration effect of the $\mathrm{ABH}$ region on the flexural wave, the flexural waves in the area on the left side of the $\mathrm{ABH}$ region did not fluctuate strongly, and most of the flexural waves were still manipulated by the $\mathrm{ABH}$ region. The concentration effect of the 2-D ABH plate on flexural waves is clearly and intuitively verified by the above numerical calculation results.

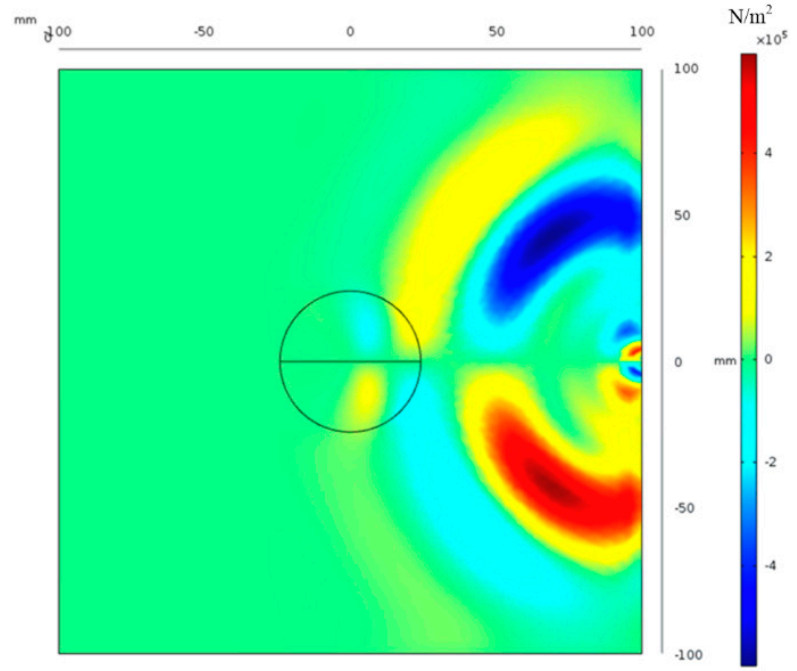

(a)

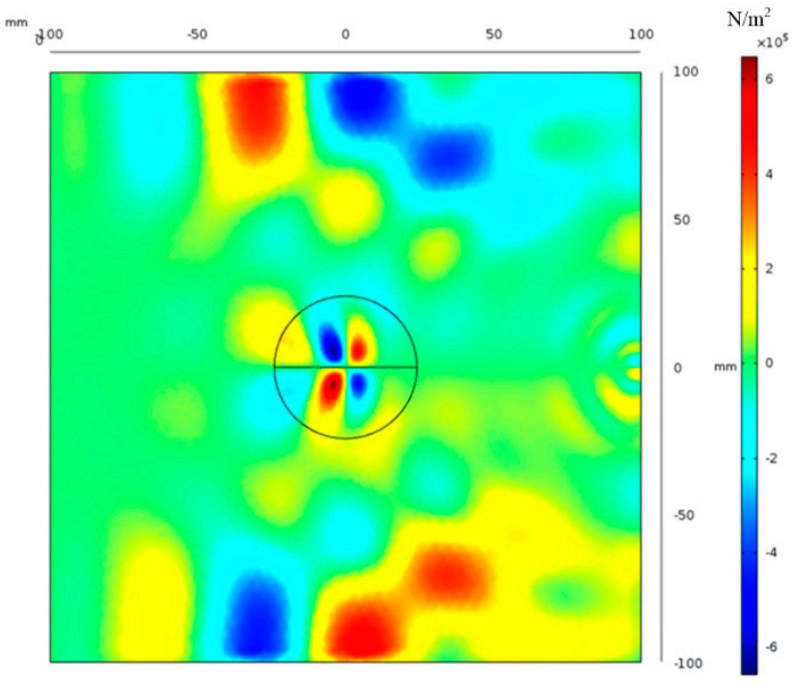

(c)

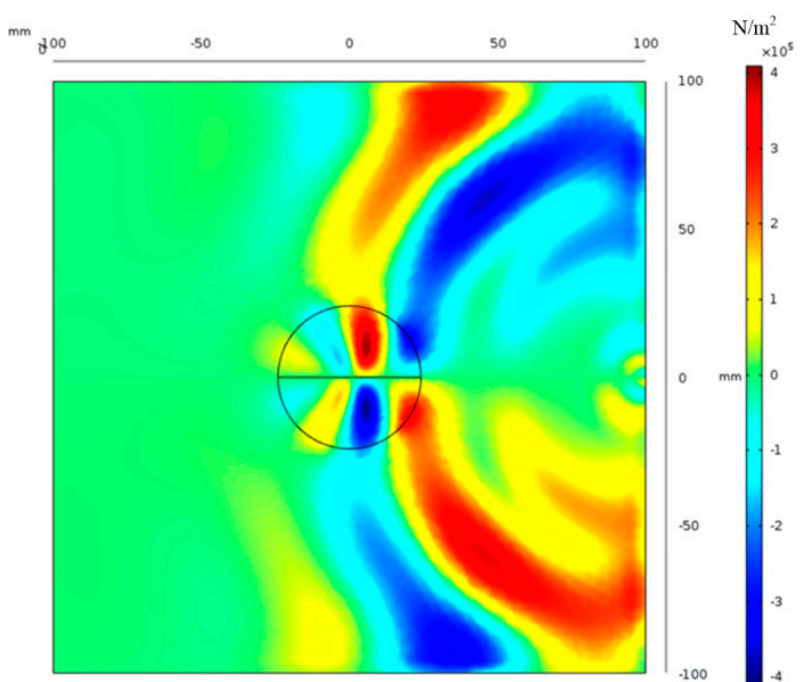

(b)

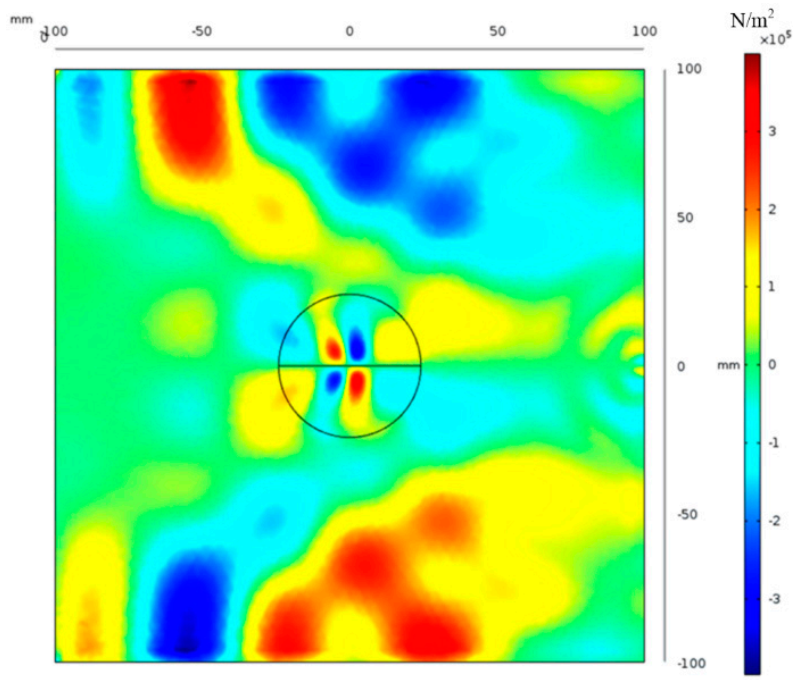

(d)

Figure 10. The propagation of flexural waves in the ABH plate at different times: (a) $t=7.5 \times 10^{-5} \mathrm{~s}$; (b) $t=1.2 \times 10^{-4} \mathrm{~s}$; (c) $t=1.95 \times 10^{-4} \mathrm{~s}$; (d) $t=2.31 \times 10^{-4} \mathrm{~s}$. 


\section{Modeling of the Support Plate Embedded with Acoustic Black Holes}

From the analysis in Section 3, it can be seen that the support plate is a key component to suppress the vibration of the refrigerator body and the radiation sound of the back wall of the refrigerator. To facilitate the subsequent meshing, the three-dimensional model of the support plate was simplified, mainly by removing chamfers, smaller openings, and more complicated small curved faces. These small geometric features have no obvious influence on the overall modes and dynamic response of the support plate, and the simplified geometric model of the support plate is shown in Figure 11. The length of the support plate is $901 \mathrm{~mm}$, the width is $203.5 \mathrm{~mm}$, and the thickness is $1.8 \mathrm{~mm}$. The four circular holes on the support plate are used to fix the compressor. The second-order tetrahedral unit C3D10 is used to mesh the support plate, and the grid size is $4 \mathrm{~mm}$. The mesh in the small curved area of the support plate is encrypted to ensure a smooth transition from small cells to large cells and the minimum cell size is $0.8 \mathrm{~mm}$ during encryption.

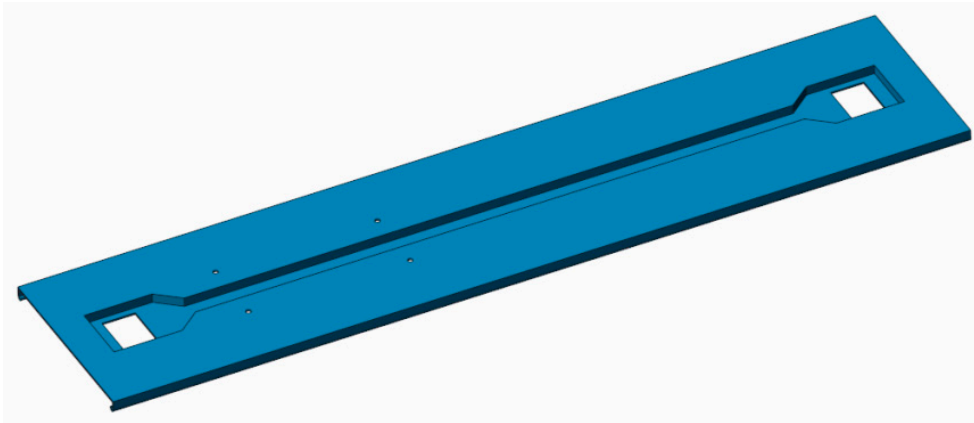

Figure 11. Simplified model of the support plate.

The $2 \times 4$ two-dimensional ABHs are embedded on the support plate, and the geometric model of the $\mathrm{ABH}$ support plate is shown in Figure 12. The geometric parameters of the two-dimensional $\mathrm{ABH}$ structure are: $\varepsilon=0.005, m=2$, and the thickness of the truncation is $0.3 \mathrm{~mm}$. It can be calculated that the outer diameter of the 2-D ABHs is $34.641 \mathrm{~mm}$ according to Equations (4) and (5). The centers of the two rows of 2-D ABHs are symmetric about the centerline of the support plate, and the distance is $120 \mathrm{~mm}$.

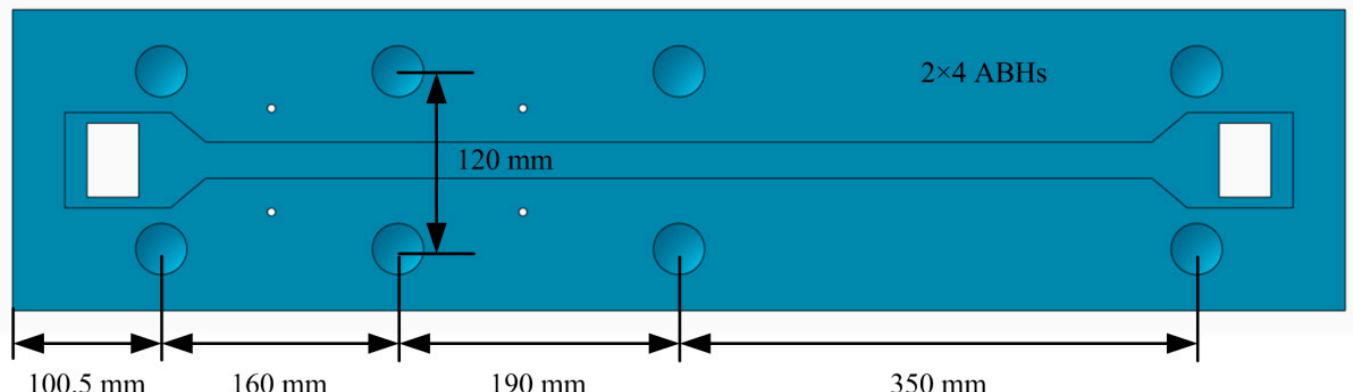

$100.5 \mathrm{~mm}$

$160 \mathrm{~mm}$

$190 \mathrm{~mm}$

$350 \mathrm{~mm}$

Figure 12. The model of the support plate embedded with 2-D ABHs.

The eight two-dimensional $\mathrm{ABH}$ regions are completely attached with damping layers with a thickness of $1.5 \mathrm{~mm}$, and the parameters of the damping material are shown in Table 2. Dynamic analysis, which can use structural damping assumptions, includes steadystate response analysis and random response analysis. The structural damping entered in the material definition is actually the loss factor of the material, and the relationship between loss factor and damping ratio is $\xi=\eta / 2$ for the Kelvin-Voigt model. When the loss factor of the viscoelastic material is obtained, the loss factor of the component made of this viscoelastic material can be evaluated. Then the damping ratio of the component and the damping coefficient of the component is obtained, which can be further used for 
structural analysis. The second-order tetrahedral unit C3D10 is used to mesh the damping $\mathrm{ABH}$ support plate. The grid size of the $\mathrm{ABH}$ regions and damping layers is $1 \mathrm{~mm}$, and the mesh in the small curved area of the $\mathrm{ABH}$ regions and damping layers is encrypted to ensure a smooth transition from small cells to large cells, and the minimum cell size is $0.2 \mathrm{~mm}$ during encryption. The grid size of the other regions of the damping $\mathrm{ABH}$ support plate is the same as that of the support plate without ABHs. The entire FEM model of the damping $\mathrm{ABH}$ support plate has a total of 821,000 grids and 236,000 nodes. Since the grids in the $\mathrm{ABH}$ regions and damping layers are very dense, for ease of display, a partial view of the upper left part of the FEM model of the damping ABH support plate is shown in Figure 13.

Table 2. Parameters of the damping material.

\begin{tabular}{ccccc}
\hline Material & $\begin{array}{c}\text { Young's } \\
\text { Modulus (Pa) }\end{array}$ & Density (kg/m $\left.\mathbf{m}^{\mathbf{3}}\right)$ & Poisson's Ratio & Loss Factor \\
\hline $\begin{array}{c}\text { Viscoelastic } \\
\text { material }\end{array}$ & $9 \times 10^{6}$ & 1812 & 0.45 & 0.4 \\
\hline
\end{tabular}

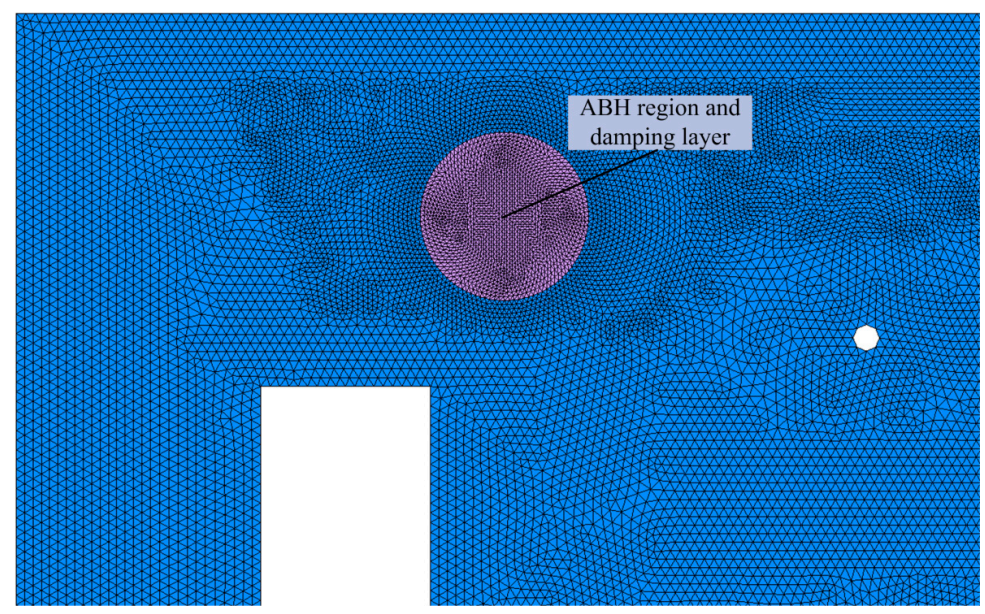

Figure 13. Partial view of the FEM model of the damping ABH support plate.

\section{Influence of ABHs on the Vibration Characteristics of the Support Plate}

Based on the FEM models established in Section 5, the modal superposition method is used to carry out the modal analysis and the vibration response calculation of the original support plate of the refrigerator and the damping ABH support plate. The left and right sides of these two support plates are clamped, and the remaining surfaces are free boundaries. The modal calculation frequency is $0 \sim 5 \mathrm{kHz}$, and Figure 14 shows the typical modes of the original support plate and the damping $\mathrm{ABH}$ support plate in the range of $0 \sim 5 \mathrm{kHz}$. It can be seen from Figure 14 that in the frequency range below $1 \mathrm{kHz}$, there is no obvious difference between the mode shapes of the damping $\mathrm{ABH}$ support plate and the mode shapes of the original support plate; only the displacement in the $\mathrm{ABH}$ regions is increased in the 13th-order mode. However, for the frequency range above $1000 \mathrm{~Hz}$, the modal distribution of the support plate was changed significantly after the damping ABHs were embedded. At the 21st, 43rd, 69th order (corresponding to the 68th order of the original support plate), due to the combined action of the 2-D ABHs and the damping layers, the modal displacement outside the $\mathrm{ABH}$ regions of the support plate was significantly reduced, and the vibration of the support plate was mainly concentrated in the $\mathrm{ABH}$ regions at these frequencies. 


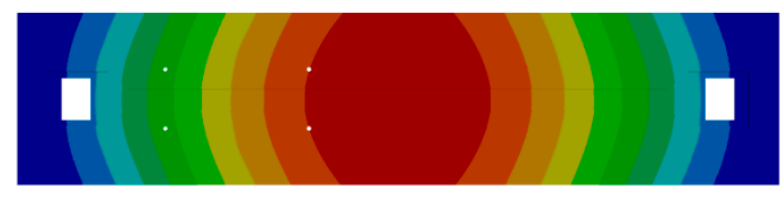

(a)

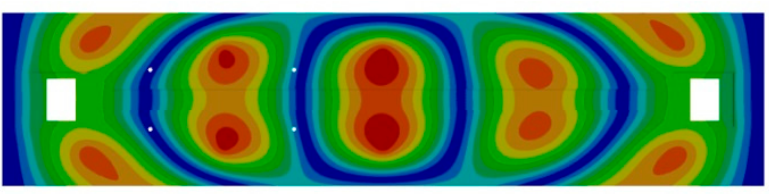

(c)

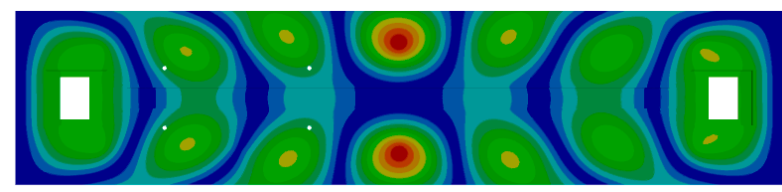

(e)

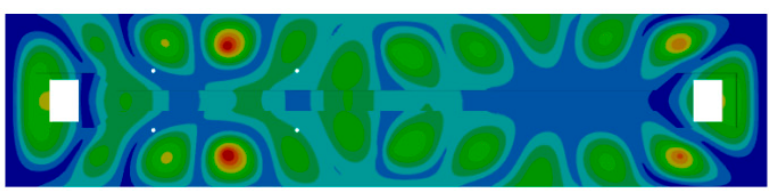

(g)

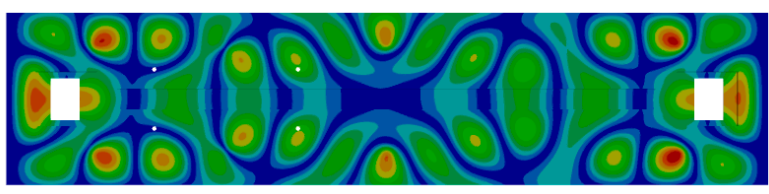

(i)

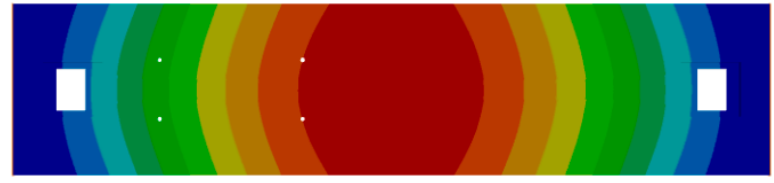

(b)

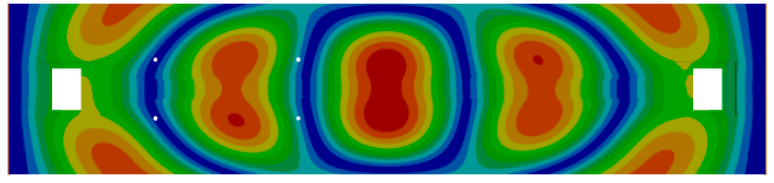

(d)

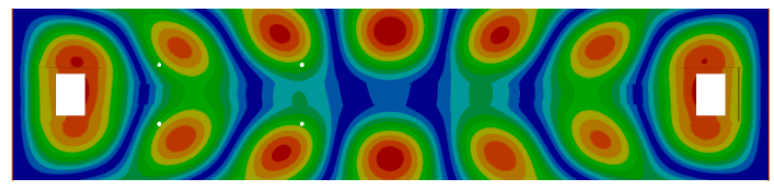

(f)

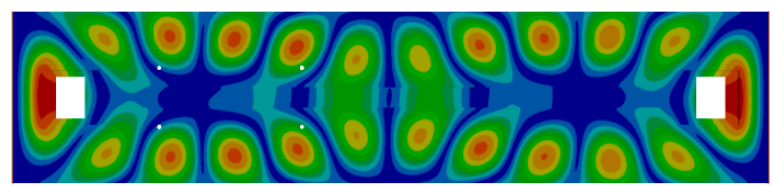

(h)

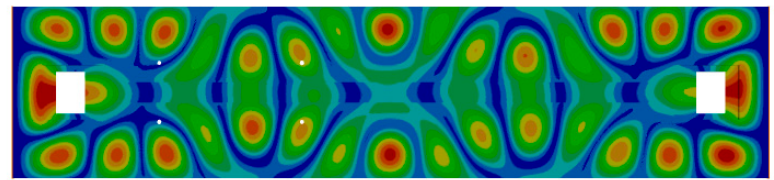

$(\mathbf{j})$

Figure 14. Modal shape comparison between the original support plate and the damping ABH support plate: (a) damping ABH support plate, first order, $73.215 \mathrm{~Hz}$; (b) original support plate, first order, $94.5 \mathrm{~Hz}$; (c) damping ABH support plate, 13th order, $937.691 \mathrm{~Hz}$; (d) original support plate, 13th order, $900.794 \mathrm{~Hz}$; (e) damping ABH support plate, 21st order, $1390.255 \mathrm{~Hz}$; (f) original support plate, 21st order, $1460.244 \mathrm{~Hz}$; (g) damping ABH support plate, 43rd order, $2588.262 \mathrm{~Hz}$; (h) original support plate, 43rd order, $2754.305 \mathrm{~Hz}$; (i) damping ABH support plate, 69th order, $3818.183 \mathrm{~Hz}$; (j) original support plate, 68th order, $4075.947 \mathrm{~Hz}$.

Taking the vibration acceleration signals of the measured points $1,2,3$, and 4 in Section 2 as the excitation input and applying the above excitation to the grid nodes corresponding to these four measuring points in the FEM models of the support plate, the vibration response of the original support plate and the damping $\mathrm{ABH}$ support plate can be obtained through numerical calculation in the commercial software LMS Virtual Lab. Figure 15 shows the vibration acceleration cloud diagram of the original support plate and the damping $\mathrm{ABH}$ support plate. It can be seen from Figure 15 that in the frequency band below $1000 \mathrm{~Hz}$, embedding damping $\mathrm{ABHs}$ has no significant effect on the vibration acceleration amplitude or distribution of the support plate. In the range of $2 \mathrm{kHz}$ to $4 \mathrm{kHz}$, most of the vibration energy is concentrated by the $\mathrm{ABH}$ regions of the damping $\mathrm{ABH}$ support plate, and the vibration acceleration of the rest of the damping $\mathrm{ABH}$ support plate is significantly reduced. In addition, the peak values of the vibration acceleration of the entire damping $\mathrm{ABH}$ support plate is much smaller than the peak values of the original support plate at the same frequencies, indicating that the 2-D damping ABHs have an obvious effect on the vibration suppression of the refrigerator support plate at these frequencies. 


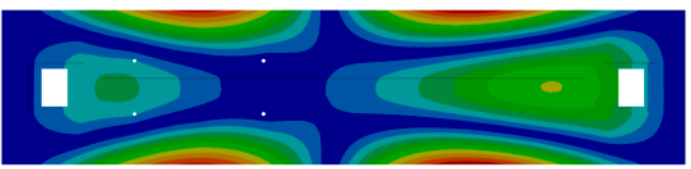

(a)

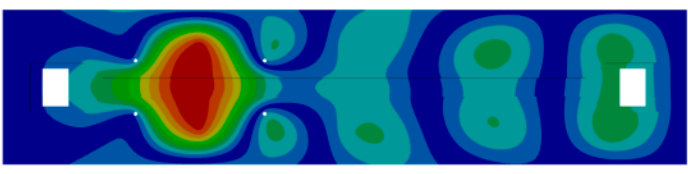

(c)

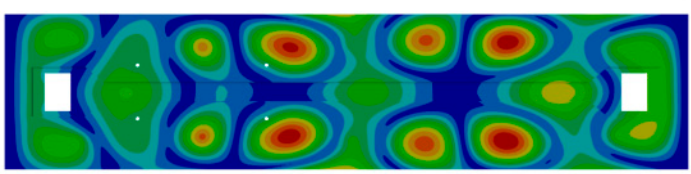

(e)

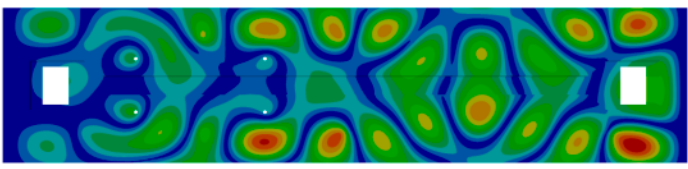

(g)

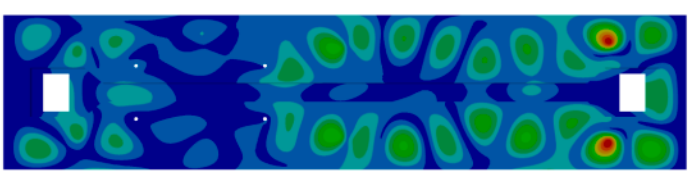

(i)

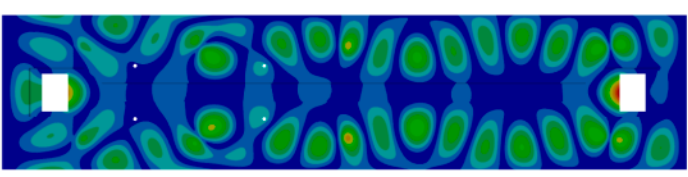

(k)

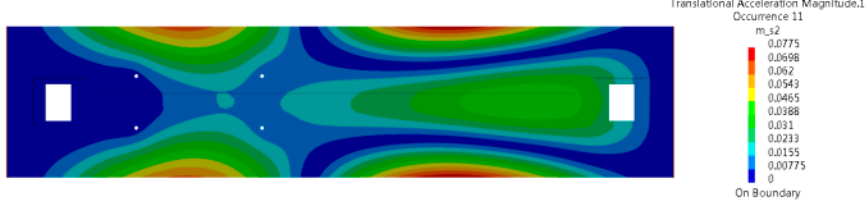

(b)

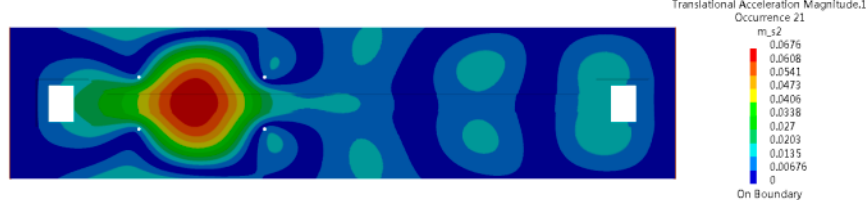

(d)

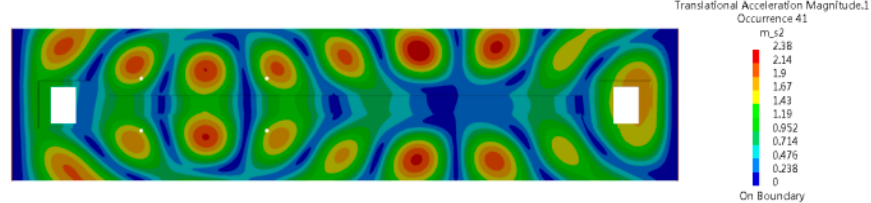

(f)
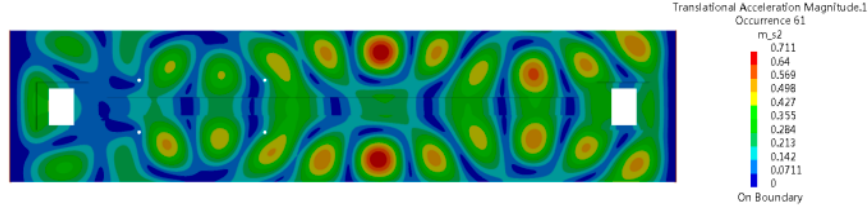

(h)
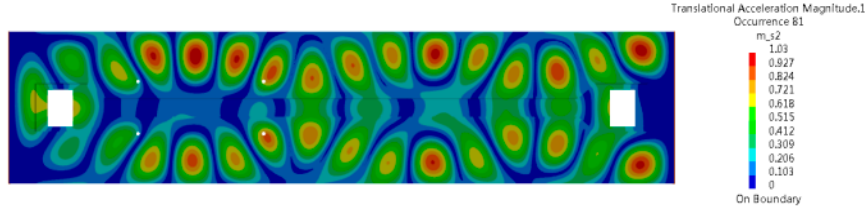

(j)
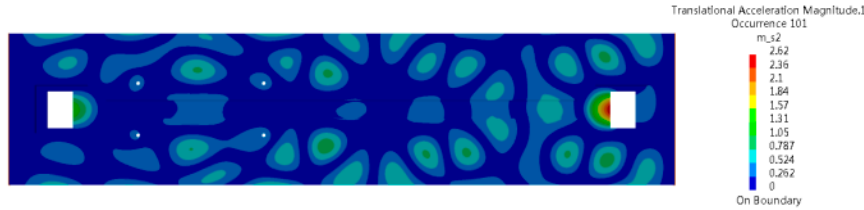

(1)

Figure 15. The vibration acceleration cloud diagram of the original support plate and the damping ABH support plate: (a) damping $\mathrm{ABH}$ support plate, $500 \mathrm{~Hz}$; (b) original support plate, $500 \mathrm{~Hz}$; (c) damping ABH support plate, $1000 \mathrm{~Hz}$; (d) original support plate, $1000 \mathrm{~Hz}$; (e) damping ABH support plate, $2000 \mathrm{~Hz}$; (f) original support plate, $2000 \mathrm{~Hz}$; (g) damping ABH support plate, $3000 \mathrm{~Hz}$; (h) original support plate, $3000 \mathrm{~Hz}$; (i) damping ABH support plate, $4000 \mathrm{~Hz}$; (j) original support plate, $4000 \mathrm{~Hz}$; (k) damping ABH support plate, $5000 \mathrm{~Hz}$; (1) original support plate, $5000 \mathrm{~Hz}$.

To better analyze the influence of the damping ABHs on the vibration acceleration of the support plate in the whole frequency band, three monitoring points were established at the left, middle and right positions of the support plate, as shown in Figure 16. 


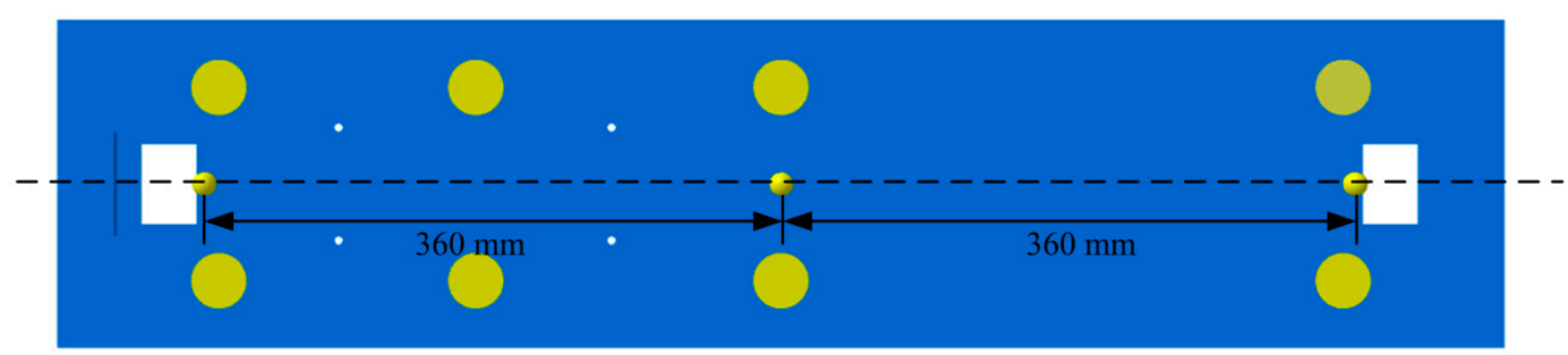

Figure 16. Schematic diagram of the location of the vibration response monitoring points.

Figures 17-19 are the vibration acceleration response spectrograms of the three monitoring points. It can be seen from Figure 17 that for the left monitoring point, the 2-D damping ABHs can significantly reduce the vibration acceleration of the refrigerator support plate in the range of $3 \mathrm{kHz}$ to $5 \mathrm{kHz}$, and the maximum attenuation value can reach $6.69 \mathrm{~dB}$ (with a reference of $0.1 \mathrm{~m} / \mathrm{s}^{2}$ ); in the $0 \sim 3 \mathrm{kHz}$ frequency band, the acceleration peak values of the left monitoring point are reduced at some frequencies but increased at other frequencies. It can be concluded from Figure 18 that for the middle monitoring point, the 2-D damping $\mathrm{ABHs}$ have no obvious suppression effect on the acceleration peak values of the support plate; however, the acceleration peak values are increased at some frequencies. It can be seen from Figure 19 that for the right monitoring point, the 2-D damping $\mathrm{ABHs}$ show a good vibration suppression effect in almost the whole frequency range, and the maximum acceleration attenuation can reach more than $10 \mathrm{~dB}$, indicating that the 2-D damping ABHs have an obvious vibration suppression effect on the right side of the support plate.

Considering that the left and right sides of the support plate are connected to the refrigerator body, and the mass and volume of the refrigerator body are much larger than the mass and volume of the support plate, it can be considered that the true boundary conditions of the support plate are basically the same as in the simulation. Combined with the sound and vibration measurement in Section 2, it can be concluded that the 2-D damping ABHs can suppress the vibrations generated by the compressor at $1390.6 \mathrm{~Hz}$, $2087.5 \mathrm{~Hz}$, and $2260.9 \mathrm{~Hz}$ from being transmitted to the refrigerator body through the support plate, thereby suppressing the radiated sound of the back wall of the refrigerator at frequencies of $1250 \mathrm{~Hz}, 2000 \mathrm{~Hz}$, and $2500 \mathrm{~Hz}$.

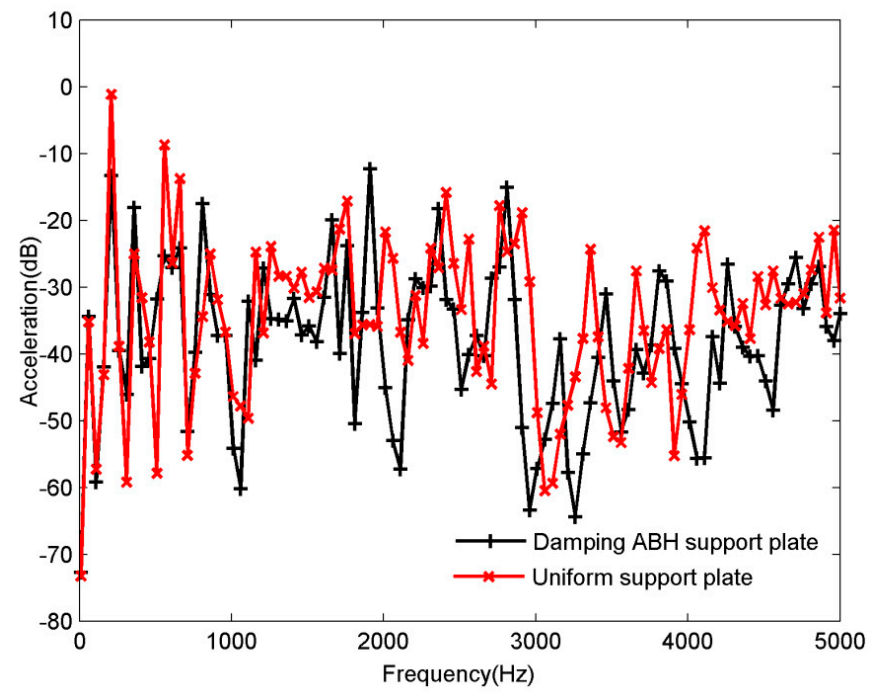

Figure 17. Acceleration response spectrum of the left monitoring point. 


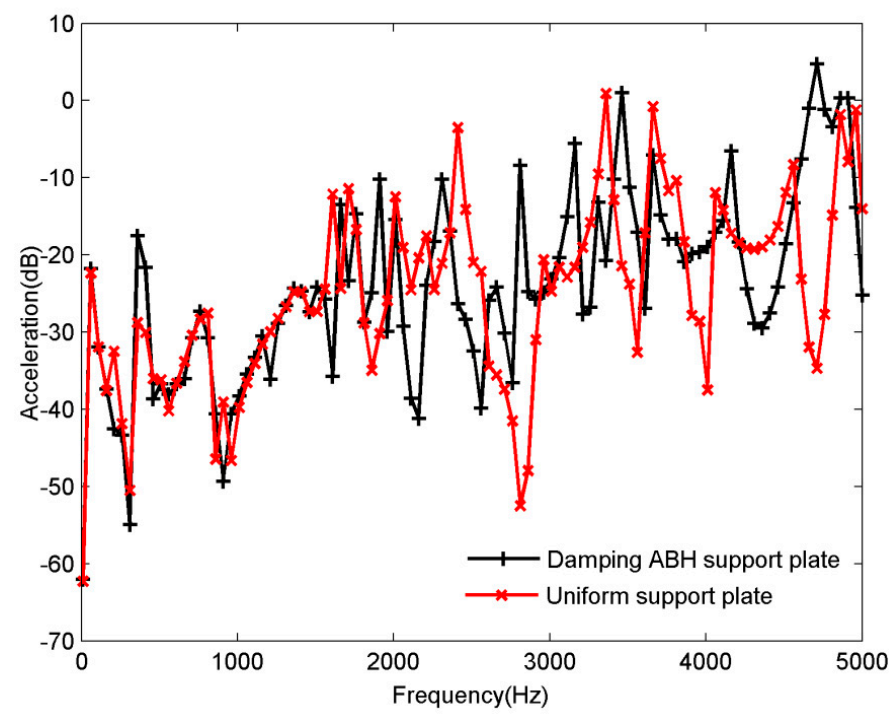

Figure 18. Acceleration response spectrum of the middle monitoring point.

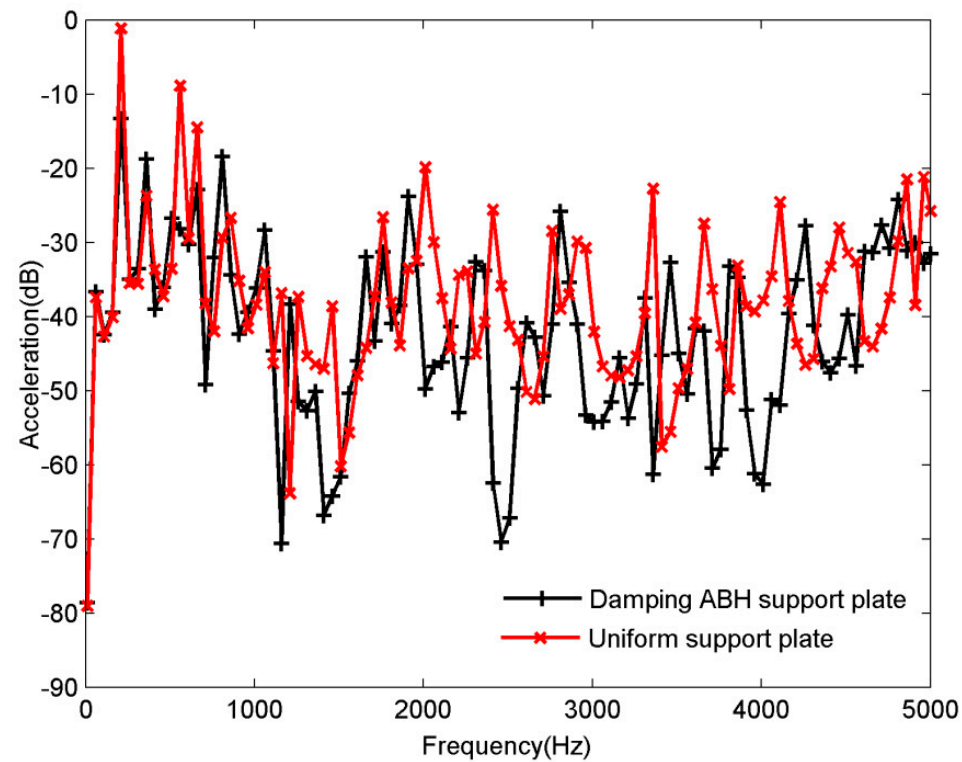

Figure 19. Acceleration response spectrum of the right monitoring point.

\section{Conclusions}

In this paper, through the vibration and noise measurement, the vibration acceleration spectrum of the compressor surface, the vibration acceleration frequency spectrum of the four positions on the support plate connected to the compressor, the vibration acceleration spectrum of the outer wall on the back of the refrigerator, and the 1/3-octave frequency spectrum of the radiated sound from the outer wall on the back of the refrigerator were obtained. In addition, the main vibration sources that cause the radiated noise of the refrigerator back wall were determined using the coherence theory analysis. By aiming at the key component of the support plate, a new solution was proposed to embed 2-D $\mathrm{ABHs}$ on the support plate to suppress the transmission of compressor vibration to the refrigerator body, thereby reducing the vibration of the refrigerator body and the sound radiated by the back wall. The concentration and manipulation effects of the 2-D ABH on flexural waves are verified by numerical simulation of flexural wave propagation in the time domain. FEM models of the original support plate and the damping ABH support plate were established to investigate the comprehensive effect of the 2-D ABHs and the 
damping layers on the vibration characteristics of the support plate through vibration mode and dynamic response analysis. The main research results are as follows:

(1). Suppressing the transmission of the support plate to the vibration of the refrigerator compressor can significantly reduce the vibration of the refrigerator body and the radiation sound of the back wall of the refrigerator;

(2). In the range of $2 \mathrm{kHz}$ to $4 \mathrm{kHz}$, most of the vibration energy is concentrated by the $\mathrm{ABH}$ regions of the damping $\mathrm{ABH}$ support plate, and the vibration acceleration of the rest of the damping $\mathrm{ABH}$ support plate is significantly reduced;

(3). The 2-D damping ABHs can suppress the vibrations generated by the compressor at $1390.6 \mathrm{~Hz}, 2087.5 \mathrm{~Hz}$, and $2260.9 \mathrm{~Hz}$ from being transmitted to the refrigerator body through the support plate, thereby suppressing the radiated sound of the back wall of the refrigerator at frequencies of $1250 \mathrm{~Hz}, 2000 \mathrm{~Hz}$, and $2500 \mathrm{~Hz}$.

Author Contributions: Conceptualization, X.D.; methodology, X.D.; software, X.D.; validation, X.D. and Q.F.; formal analysis, X.D.; investigation, X.D.; writing-original draft preparation, X.D.; writing-review and editing, X.D., J.Z. and C.Z. All authors have read and agreed to the published version of the manuscript.

Funding: This research was funded by the National Key Research and Development Program of China, grant number 2019YFB2006402.

Institutional Review Board Statement: Not applicable.

Informed Consent Statement: Not applicable.

Data Availability Statement: All data included in this study are available upon request from the corresponding author.

Conflicts of Interest: The authors declare no conflict of interest.

\section{References}

1. Ji, H.; Han, B.; Cheng, L.; Inman, D.J.; Qiu, J. Frequency attenuation band with low vibration transmission in a finite-size plate strip embedded with 2D acoustic black holes. Mech. Syst. Signal Process. 2022, 163, 108149. [CrossRef]

2. Gao, N.S.; Guo, X.Y.; Deng, J.; Cheng, B.Z.; Hou, H. Elastic wave modulation of double-leaf ABH beam embedded mass oscillator. Appl. Acoust. 2021, 173, 107694. [CrossRef]

3. Pelat, A.; Gautier, F.; Conlon, S.C.; Semperlotti, F. The acoustic black hole: A review of theory and applications. J. Sound Vib. 2020, 476, 115316. [CrossRef]

4. Ma, L.; Cheng, L. Numerical and experimental benchmark solutions on vibration and sound radiation of an Acoustic Black Hole plate. Appl. Acoust. 2020, 163, 107223. [CrossRef]

5. Li, H.Q.; Touze, C.; Gautier, F.; Pelat, A. Linear and nonlinear dynamics of a plate with acoustic black hole, geometric and contact nonlinearity for vibration mitigation. J. Sound Vib. 2021, 508, 116206. [CrossRef]

6. Mironov, M.A. Propagation of a flexural wave in a plate whose thickness decreases smoothly to zero in a finite interval. Sov. Phys. Acoust.-USSR 1988, 34, 318-319.

7. Krylov, V.V. Conditions for validity of the geometrical-acoustics approximation in application to waves in an acute-angle solid wedge. Sov. Phys. Acoust.-USSR 1989, 35, 176-180.

8. Krylov, V.V.; Tilman, F. Acoustic 'black holes' for flexural waves as effective vibration dampers. J. Sound Vib. 2004, 274, 605-619. [CrossRef]

9. Krylov, V.V.; Winward, R. Experimental investigation of the acoustic black hole effect for flexural waves in tapered plates. J. Sound Vib. 2007, 300, 43-49. [CrossRef]

10. Du, X.F.; Huang, D.C.; Zhang, J.R. Dynamic Property Investigation of Sandwich Acoustic Black Hole Beam with Clamped-Free Boundary Condition. Shock Vib. 2019, 2019, 6708138. [CrossRef]

11. Tang, L.L.; Cheng, L.; Ji, H.L.; Qiu, J.H. Characterization of acoustic black hole effect using a one-dimensional fully-coupled and wavelet-decomposed semi-analytical model. J. Sound Vib. 2016, 374, 172-184. [CrossRef]

12. Tang, L.L.; Cheng, L. Enhanced Acoustic Black Hole effect in beams with a modified thickness profile and extended platform. J. Sound Vib. 2017, 391, 116-126. [CrossRef]

13. Deng, J.; Zheng, L.; Zeng, P.Y.; Zuo, Y.F.; Guasch, O. Passive constrained viscoelastic layers to improve the efficiency of truncated acoustic black holes in beams. Mech. Syst. Signal Process. 2019, 118, 461-476. [CrossRef]

14. Deng, J.; Zheng, L.; Guasch, O.; Wu, H.; Zeng, P.Y.; Zuo, Y.F. Gaussian expansion for the vibration analysis of plates with multiple acoustic black holes indentations. Mech. Syst. Signal Process. 2019, 131, 317-334. [CrossRef] 
15. Deng, J.; Guasch, O.; Zheng, L. Ring-shaped acoustic black holes for broadband vibration isolation in plates. J. Sound Vib. 2019, 458, 109-122. [CrossRef]

16. Ma, L.; Zhang, S.; Cheng, L. A 2D Daubechies wavelet model on the vibration of rectangular plates containing strip indentations with a parabolic thickness profile. J. Sound Vib. 2018, 429, 130-146. [CrossRef]

17. O'Boy, D.J.; Krylov, V.V.; Kralovic, V. Damping of flexural vibrations in rectangular plates using the acoustic black hole effect. $J$. Sound Vib. 2010, 329, 4672-4688. [CrossRef]

18. O'Boy, D.J.; Krylov, V.V. Damping of flexural vibrations in circular plates with tapered central holes. J. Sound Vib. 2011, 330, 2220-2236. [CrossRef]

19. Conlon, S.C.; Feurtado, P.A. Progressive phase trends in plates with embedded acoustic black holes. J. Acoust. Soc. Am. 2018, 143, 921-930. [CrossRef]

20. Zhao, L.X.; Semperlotti, F. Embedded Acoustic Black Holes for semi-passive broadband vibration attenuation in thin-walled structures. J. Sound Vib. 2017, 388, 42-52. [CrossRef]

21. Gao, N.S.; Wei, Z.Y.; Hou, H.; Krushynska, A.O. Design and experimental investigation of V-folded beams with acoustic black hole indentations. J. Acoust. Soc. Am. 2019, 145, EL79-EL83. [CrossRef] [PubMed]

22. Feurtado, P.A.; Conlon, S.C. An Experimental Investigation of Acoustic Black Hole Dynamics at Low, Mid, and High Frequencies. J. Vib. Acoust.-Trans. ASME 2016, 138, 061002. [CrossRef]

23. Bowyer, E.P.; Krylov, V.V. Slots of Power-Law Profile as Acoustic Black Holes for Flexural Waves in Metallic and Composite Plates. Structures 2016, 6, 48-58. [CrossRef]

24. Bowyer, E.P.; O’Boy, D.J.; Krylov, V.V.; Gautier, F. Experimental investigation of damping flexural vibrations in plates containing tapered indentations of power-law profile. Appl. Acoust. 2013, 74, 553-560. [CrossRef]

25. Bowyer, E.P.; Krylov, V.V. Experimental investigation of damping flexural vibrations in glass fibre composite plates containing one- and two-dimensional acoustic black holes. Compos. Struct. 2014, 107, 406-415. [CrossRef]

26. Ning, L.; Wang, Y.Z.; Wang, Y.S. Concentrating and black hole like structures by elastic metamaterials with acoustic cavities under active feedback control. Waves Random Complex Media 2020. [CrossRef]

27. Ning, L.; Wang, Y.Z.; Wang, Y.S. Active control of a black hole or concentrator for flexural waves in an elastic metamaterial plate Mech. Mater. 2020, 142, 103300. [CrossRef]

28. Ji, H.; Huang, W.; Qiu, J.; Cheng, L. Mechanics problems in application of acoustic black hole structures. Adv. Mech. 2017, 47, 333-384.

29. Zhou, H.H.; Mao, Y.J.; Diao, Q.; Lu, F.A.; Zhang, Q.L. Numerical analysis of the vibration and noise induced by the unsteady flow in a centrifugal compressor. Proc. Inst. Mech. Eng. Part A-J. Power Energy 2016, 230, 554-569. [CrossRef]

30. Du, X.F.; Zong, C.Y.; Fu, Q.D.; Zhang, J.R. CFD Analysis and Optimization of Effect of Shroud with Multi-outlets on Airflow Uniformity in a Frost-Free Refrigerator. J. Appl. Fluid Mech. 2021, 14, 37-48. [CrossRef]

31. Shu, G.Q.; Liang, X.Y. Identification of complex diesel engine noise sources based on coherent power spectrum analysis. Mech. Syst. Signal Process. 2007, 21, 405-416. [CrossRef]

32. Du, X.F.; Huang, D.C.; Fu, Q.D.; Zhang, J.R. Effects of Acoustic Black Hole Parameters and Damping Layer on Sound Insulation Performance of ABH Circular Plate. Appl. Sci. 2019, 9, 5366. [CrossRef] 